\title{
Reading versus naming: The effect of target set size on contextual interference and facilitation
}

\author{
WIDO LA HEIJ and MARJOLEIN VERMEIJ \\ University of Leiden, Leiden, The Netherlands
}

\begin{abstract}
Reading and naming tasks are differentially affected by variations in target set size. In naming tasks, response latencies strongly increase with set size, whereas in reading tasks, no, or only minor, increases are found. The results of a number of studies suggest that reading and naming tasks also differ in the effect of target set size on contextual interference and facilitation. In this study, target set size was manipulated in letter-reading and picture-naming tasks that were in all further respects as similar as possible. Four distractor conditions were used: incongruent, neutral, control, and congruent. Apart from differential effects of set size on overall mean reaction time, the reading and naming tasks showed similar results. With increasing target set size, interference due to an incongruent distractor decreased and facilitation due to a congruent distractor increased. This interference-facilitation tradeoff was obtained regardless of whether the neutral condition or the control condition was used as a baseline. A logogen model is presented that accounts for these changes in context effects in terms of differences in criterion level and rate of accumulation of activation.
\end{abstract}

In one of the experimental paradigms used to investigate the processes involved in reading and naming and the function of selective attention, subjects have to react to a target stimulus that is accompanied by one or more distractors, or noise elements. In this paper, two variants of this experimental paradigm will be examined. In the first variant (henceforth called the NVB variant), the target stimulus is nonverbal, often a color or a picture, whereas the distractor is a word. The Stroop task, in which subjects name a color that is accompanied by a word, (e.g., M. O. Glaser \& W. R. Glaser, 1982; Stroop, 1935) and the picture-word interference task (e.g., Lupker, 1979; Rosinski, Golinkoff, \& Kukish, 1975) are the two most common examples of this variant.

In the second variant (henceforth called the VB variant) both the distractor and the target are of a verbal nature. Examples of this variant are tasks in which a target letter is accompanied by one or more distractor letters (e.g., B. A. Eriksen \& C. W. Eriksen, 1974; C. W. Eriksen \& Schultz, 1979; Flowers \& Wilcox, 1982; Grice, Boroughs, \& Canham, 1984; Proctor \& Fober, 1985; Taylor, 1977) and tasks referred to as "word-word variants of the Stroop task," in which one of two presented words has to be read aloud (e.g., M. O. Glaser \& W. R. Glaser, 1982; La Heij, Van der Heijden, \& Schreuder, 1985; Van der Heijden, 1981).

In both the NVB variant and the VB variant, four distractor conditions are often used. In the first condition, the target element is accompanied by a distractor that (1) belongs to the set of target elements used in the experiment (VB), or is the verbal label of one of the targets

Requests for reprints should be sent to W. La Heij, Department of Psychology, Unit of Experimental Psychology, University of Leiden, Hooigracht 15, 2312 KM Leiden, The Netherlands. in the experiment (NVB), (2) belongs to the same semantic domain as the accompanying target, and (3) is associated with a response that is different from the appropriate response to the accompanying target. Examples of this condition in the NVB variant are: the word RED in blue ink when the color red is used as one of the targets in the experiment (e.g., Stroop, 1935); the picture of a table accompanied by the word CHAIR, when one of the alternative targets in the experiment is the picture of a chair (e.g., W. R. Glaser \& Düngelhoff, 1984; Guttentag \& Haith, 1978). Examples in the VB variant are: the target word RED accompanied by the distractor word BLUE, when the word BLUE is one of the alternative target words in the experiment (e.g., Van der Heijden, 1981); the target letter $\mathrm{K}$ accompanied by the distractor letter $T$ when the letter $T$ is an alternative target letter associated with a different response in the experiment (e.g., Taylor, 1977). This condition will be referred to as the incongruent (INC) condition.

In the second distractor condition, the distractor (1) does not belong to the set of targets used in the experiment (VB), or is not the verbal label of one of these targets (NVB), and (2) belongs to the same semantic domain as the accompanying target. An example of this condition in the NVB variant is: the word PURPLE in green ink when the color purple is not used as a target in the experiment (e.g., Klein, 1964; Proctor, 1978). An example in the VB variant is: the target $K$ accompanied by the distractor $O$ when $O$ is not one of the target letters (e.g., Taylor, 1977). This condition will be referred to as the neutral (NEU) condition.

In the third distractor condition, the target is presented in isolation or is accompanied by a distractor element that is as neutral as possible with respect to the task demands. In the color-word and word-word variants of the Stroop 
task and in the picture-word task, often a row of Xs is used. In the letter-identification task, sometimes nonalphanumeric distractors such as \# or * are used (e.g., Flowers \& Wilcox, 1982; Proctor \& Fober, 1985; Stirling $\&$ Coltheart, 1977). This condition will be referred to as the control (CONTR) condition.

In the fourth distractor condition, the target is accompanied by a distractor that is identical to the target (VB) or is the verbal label of the accompanying target (NVB). Examples of this condition in the NVB variant are: the word RED printed in the color red (e.g., M. O. Glaser \& W. R. Glaser, 1982); the picture of a horse accompanied by the word HORSE (e.g, W. R. Glaser \& Düngelhoff, 1984; Rosinski et al., 1975). In the VB variant, examples are: the target word BLUE accompanied by the distractor word BLUE (e.g., M. O. Glaser \& W. R. Glaser, 1982; Van der Heijden, 1981); the target letter $\mathrm{K}$ accompanied by the distractor letter $\mathrm{K}$ (e.g., Taylor, 1977). This condition will be referred to as the congruent (CONGR) condition.

The mean response latencies obtained in experiments in which these different conditions are compared often show a decrease in the following order: INC, NEU, CONTR, and CONGR. The differences in mean response latency between these distractor conditions are usually labeled "facilitation" and "interference." In most Stroop tasks, picture-word interference tasks, and a number of letter-identification tasks (Flowers \& Wilcox, 1982; Stirling \& Coltheart, 1977), interference and facilitation are defined as INC-CONTR and CONTR-CONGR, respectively. In other letter-identification tasks, however, interference and facilitation are defined as INC-NEU and NEU-CONGR, respectively (e.g., Taylor, 1977).

Although the sizes of the latency differences among the four conditions vary appreciably between the VB and NVB variants of the task, the similarity of the general pattern of results obtained in both variants is striking. In recent studies, additional similarities have been reported. M. O. Glaser and W. R. Glaser (1982) found that the time courses of interference effects (obtained by varying the onset of target and distractor) are very similar for the color-word and word-word variants of the Stroop task. La Heij et al. (1985) reported that in a VB variant of the task a distractor that is semantically associated with one of the incorrect response alternatives results in a larger response latency than obtained in the control condition. This finding is in agreement with the results of an NVB variant reported by Klein (1964), showing that a word such as SKY (associated with the response blue) interferes with the naming of, for example, the color green.

On the basis of these similarities between the VB and NVB variants of the task, a number of authors have conjectured that the processes underlying the interference effect in both variants are similar (see M. O. Glaser \& W. R. Glaser, 1982; La Heij et al., 1985; Van der Heijden, 1981). One experimental finding, however, that seems to be at variance with this conjecture concerns the effect of number of target alternatives on the size of the distractor effects. We will discuss the effects of this manipulation in the VB and NVB variants of the task, in turn.

In the VB variant, the number of target alternatives has been manipulated by Taylor (1977), Proctor and Fober (1985), and La Heij et al. (1985). In his second experiment, Taylor (1977) used a letter-identification task in which $K$ and $T$ were the targets and $O$ was the neutral distractor letter. Subjects had to press one of two buttons dependent upon whether the target $\mathrm{K}$ or the target $\mathrm{T}$ appeared in the center of a three-letter array. The other two positions in the array were filled with the alternative target (INC condition), with the neutral distractor letter (NEU condition), or with a letter identical to the target (the CONGR condition). In his third experiment, Taylor increased the number of target alternatives to four. The four letters that served as targets were assigned in pairs to each of the response buttons. The results of this increase in number of target alternatives were: (1) an increase in overall mean response latency, (2) a decrease in interference (defined as INC-NEU), and (3) an increase in facilitation (defined as NEU-CONGR) in the majority of the stimulus onset asynchrony conditions used in the experiment. Similar results were obtained in the letter-identification tasks used by Proctor and Fober (1985). When their control condition (in which an asterisk was used as the distractor) is used as a baseline, interference decreases and facilitation increases with increasing target set size.

These findings are completely in accordance with La Heij et al.'s (1985) results. These authors increased the number of target alternatives in a version of the wordword variant of the Stroop task. The four distractor conditions used were the ones discussed above. With increasing target set size, the results showed: (1) an overall increase in mean response latency, (2) a decrease in interference, both when defined as INC - NEU and when defined as INC-CONTR, and (3) an increase in facilitation (defined as CONTR-CONGR). Apparently, these effects of set size are independent of response mode (manual in Taylor's and Proctor and Fober's experiments and verbal in La Heij et al.'s experiment), and they are obtained both when only the target set size is increased (Proctor \& Fober, 1985; Taylor, 1977) and when the response set size is increased as well (La Heij et al., 1985).

The Stroop task is the only task of the NVB variant in which the number of target alternatives has been systematically manipulated. The results of this manipulation are equivocal, however: Interference was either unaffected (Gholson \& Hohle, 1968a; Golden, 1974; McClain, 1983; Ray, 1974) or increased with target set size (Williams, 1977). The few studies that have examined facilitation effects also show discrepant results: McClain (1983) ob- 
tained no effect of set size on facilitation values, whereas Williams (1977) reported that facilitation increased with set size.

Taken together, varying the size of the target set seems to affect the pattern of results in the VB and NVB variants of the task in different ways. This discrepancy is most evident in the interference effect. In the VB variant, interference decreases with increasing set size, whereas in the NVB variant, interference is unaffected or increases with set size.

It is a well-established fact that naming times increase strongly with set size (Fraisse, 1969; Gholson \& Hohle, $1968 \mathrm{~b}$ ), whereas reading times are unaffected (Fraisse, 1969) or show only a small increase with set size (Gellatly \& Gregg, 1974; Gholson \& Hohle, 1968b). Given this difference between reading and naming, Ray (1974) argued that an increase of target set size in the Stroop task would affect the verbal response latency to the color but hardly at all the verbal response latency to the word. If the amount of interference depends upon the order in which the responses associated with the target and the distractor become activated, and upon the time interval between these two activations, a change in interference with increasing set size could be expected. We will return to this interpretation in the General Discussion.

The main purpose of the present paper was to make sure that the observed discrepancy was not due to the rather large number of procedural differences between the VB and NVB variants of the task reported in the literature. Here we will mention just one of them. In a number of the studies discussed above, different target-distractor pairs were used in the different set size conditions. Williams (1977), for example, used the colors and color words BLUE and GREEN in the smallest set size condition and BLUE, GREEN, ORANGE, GOLD, RED, PINK, BROWN, and BLACK in the largest. Consequently, in the latter condition, target-distractor pairs were presented that had not been used in the two-color condition. Some of these pairs might show a different amount of interference due to, for example, a greater physical similarity between the color and the color denoted by the word (e.g., RED-ORANGE). Since this effect is less likely to occur in the VB variant, it could be responsible for the observed discrepancy. It is noteworthy in this respect that Gholson and Hohle (1968a), who analyzed only the color-word combinations that were common to both set size conditions, did not obtain an effect of set size on the amount of interference.

In the present study, the same experimental design and procedure were used in a VB and an NVB variant of the task. In Experiment 1, a letter-reading task was used; in Experiment 2, a picture-naming task was used. The design employed by La Heij et al. (1985) was chosen. In this design, the stimulus material in the various set size conditions is identical. The only difference between the set size conditions is in the way in which the material is assigned to blocks of trials.

\section{EXPERIMENT 1}

In the first experiment, we attempted to replicate the findings of Proctor and Fober (1985), Taylor (1977), and La Heij et al. (1985)-a decrease in interference and an increase in facilitation with an increasing number of target alternatives-in a letter-reading task. The experiment differed from these previous studies in a number of respects. First, unlike the experiments of Proctor and Fober (1985) and Taylor (1977), a reading response was required. Consequently, the number of target alternatives was equal to the number of response alternatives. Second, unlike the experiment of Taylor (1977), a control condition with a nonalphanumeric character was used in addition to the INC, NEU, and CONGR conditions used in his study. Third, unlike the experiment of La Heij et al. (1985), letters were used instead of words.

Since we were interested in the effects of target set size on both facilitation and interference, a stimulus onset asynchrony between distractor and target was chosen at which both effects were expected to show up. The results of Flowers and Wilcox (1982), Grice et al. (1984), and Taylor (1977) had indicated that this was probably the case when the distractor was presented $50 \mathrm{msec}$ before the target. The target set sizes chosen in this study were two, four, and eight.

\section{Method}

Subjects. Twelve University of Leiden students served as paid subjects. All had normal or corrected-to-normal vision.

Materials. Table 1 shows the four triads of consonants that were used in the experiment. Two of the letters in a triad were used both as targets and as distractors, one letter was used only as a distractor. An interletter confusion matrix of the capitals generated by the Vector General system (Van der Heijden, Malhas, \& Van den Roovaart, 1984), was used in assigning the consonants to the various sets. Two demands were met as closely as possible: (1) The mean confusability between the letters within the target set was to equal the mean confusability between the target letters and the neutral distractor letters, and (2) the confusability between the two target letters in each triad was to equal the mean confusability between the two target letters and the corresponding neutral distractor letter.

The following distractor conditions were used: (1) Incongruent (INC)-In this condition, the target letter was accompanied by the alternative target letter from the same row in Table 1 (e.g., target $S$ with distractor K). (2) Neutral (NEU) - In this condition, the target letter was accompanied by the neutral distractor letter from the same row in Table 1 (e.g., target $F$ with the distractor $N$ ). (3) Control (CONTR) - In this condition, the target letter was accompanied by a \# sign. (4) Congruent (CONGR)-In this condition, the target letter was accompanied by an identical distractor (e.g., target C

Table 1 Stimulus Material Used in Experiment 1

\begin{tabular}{ccc} 
Targets/ & Neutral & \\
Distractors & Distractors & Control \\
\hline L T & J & $\#$ \\
K S & D & $\#$ \\
C M & B & $\#$ \\
V F & N & $\#$ \\
\hline
\end{tabular}

Note-Stimuli were combinations of characters within the same row. 
with distractor $\mathrm{C}$ ). Each of the 32 target-distractor combinations (eight targets $\times$ four distractor conditions) was presented eight times in each of the three set size conditions-four times with the target above and four times with the target below the point of fixation. The size of the letters was $.29^{\circ} \times .34^{\circ}$ of visual angle. The distance between the closest contours of the target and distractor was $.57^{\circ}$.

Apparatus. The stimuli were white uppercase letters presented on a fast display screen (Vector General). Naming latency, reaction time (RT), was determined with an accuracy of 1 msec by means of a voice key. Stimulus presentation and registration of RTs and number of errors were controlled by a PDP-11/34 computer.

Procedure. Each of the 12 subjects served in each of the three target set size conditions. The order in which they received these conditions was completely balanced (six possible orders, with 2 subjects assigned to each). These conditions were run in separate sessions with at least 1 day in between. The 256 experimental trials in each session ( 8 target letters $\times 4$ distractor conditions $\times 2$ positions $\times 4$ replications) were divided into four blocks of 64 trials. Each block consisted of 16 trials from each of the four distractor conditions (INC, NEU, CONTR, and CONGR).

In the two-target condition, only stimulus material from one of the rows in Table 1 was used in each block-for example, in the first block, L, T, J, and \#, in the second block, $K, S, D$, and \#, and so forth. The order in which the letter-block combinations were presented was balanced over subjects by means of three different Latin squares. In the four-target condition, stimulus material from two of the rows in Table 1 was used in each block. The targets in Block 1 were identical to those in Block 2 (e.g., L, T, K, and $S)$, but the stimuli were presented in a different random order. The same was true for the targets in Blocks 3 and 4 (e.g., C, M, V, and F). In this way, Block 2 was a replication of Block 1 , and Block 4 was a replication of Block 3 . All possible combinations of two rows from Table 1 were used and assigned randomly to the subjects. In the eight-target condition, stimulus material from each of the four rows in Table 1 was presented in each of the blocks. So, in this condition, each of the blocks consisted of the same set of stimuli and the blocks represented four replications. It should be noted that the 256 stimuli used in Set Size Conditions 2, 4, and 8 were identical. The only difference was that in each block two, four, or eight targets could occur.

The subjects were run individually in a dimly illuminated room. Viewing distance was $1 \mathrm{~m}$. All subjects got acquainted with the task in a series of 25 practice trials. The stimuli used in this series were drawn from the stimulus material that would be presented in the first experimental block.

A trial involved the following sequence: Two horizontal bars, $.97^{\circ}$ of visual angle apart (inside to inside), appeared on the screen. The length of each bar was $2.12^{\circ}$. A dim asterisk in the center of the space between the two bars served as fixation point. The subjects were told to look at this point and to press a push button to initiate the trial. The distractor appeared between the two bars 500 msec after the push button was pressed. The target letter appeared either below or above the distractor $50 \mathrm{msec}$ after distractor onset. Target duration was $100 \mathrm{msec}$. During this period, the distractor and the bars remained on the screen. The subject was instructed to read the letter that was presented second and localized either above or below the central distractor character as quickly as possible while retaining accuracy. The subject was told to ignore the distractor character. If necessary, information about the new set of target and distractor letters was given before the start of each block. Each block was preceded by eight warm-up trials. The results of the practice and warm-up trials were not included in the analyses.

RTs were measured from the onset of the target letter. The experimenter entered a code into the computer to indicate whether the response was correct or false. A distinction was made between incorrect responses and cases in which the voice key failed to trigger or triggered too early. To reduce variance in the data, each incorrect response was followed by a filler trial. The results of these filler trials were not included in the analyses. After the code had been entered into the computer and an additional 2-sec interval had elapsed, the bars and fixation point reappeared.

\section{Results}

The raw data were treated as follows: First, RTs longer than 1,000 msec were excluded. Next, for each subject, means and standard deviations were calculated for each of the 12 experimental conditions (three set sizes $\times$ four distractor conditions). Next, RTs that deviated by more than three standard deviations from their cell mean were excluded. The remaining RTs were used in the calculation of the means per subject. The 1,000-msec criterion, the 3-SD criterion, and the trials in which the voice key failed to trigger or triggered too early accounted for $0.2 \%$, $0.9 \%$, and $0.4 \%$ of the data, respectively. Table 2 shows the mean RTs and percentages of errors in the various conditions (see also Figure 1). Since the error percentages were small and generally in accordance with the results of the response latency measures, no statistical analysis was performed on these data.

An overall analysis of variance was run over the mean RTs with order of presentation of the different set sizes as the between-subjects factor and set size $(2,4,8)$ and distractor conditions (INC, NEU, CONTR, and CONGR) as within-subjects factors. Significant main effects were obtained for the factor set size $[F(2,12)=4.6, p<.05]$ (mean RTs were 486, 495, and $500 \mathrm{msec}$ in Set Size Conditions 2,4 , and 8 , respectively) and for the factor distractor conditions $[F(3,18)=57.7, p<.001]$ (mean RTs were $520,502,488$, and $464 \mathrm{msec}$ in the INC, NEU, CONTR, and CONGR conditions, respectively). Interaction effects were obtained between the factors of order of presentation of the set size conditions and set size $[F(10,12)=4.9, p<.01]$ (this reflects a decrease of overall mean RT with days) and between the factors of set size and distractor conditions $[F(6,36)=6.6$, $p<.001]$. The RTs corresponding to the latter interaction are given in Table 2.

Since the experimental question concerned the effects of set size on interference and facilitation, separate analyses of variance were run over the difference scores INC-NEU, INC-CONTR, INC-CONGR, NEUCONTR, NEU - CONGR, and CONTR-CONGR, with

Table 2

Mean Reaction Times in Milliseconds and Percentages of Errors (in Parentheses) per Target Set Size and Distractor Condition in Experiment 1

\begin{tabular}{ccccc}
\hline & \multicolumn{4}{c}{ Distractor Condition } \\
\cline { 2 - 5 } Set Size & Incongruent & Neutral & Control & Congruent \\
\hline 2 & $519(4.9)$ & $493(1.0)$ & $475(0.7)$ & $456(0.5)$ \\
4 & $520(3.5)$ & $500(1.0)$ & $492(0.8)$ & $468(1.0)$ \\
8 & $523(4.0)$ & $512(1.8)$ & $498(1.6)$ & $468(1.2)$ \\
\hline
\end{tabular}


target set size as the within-subjects factor (see Table 5 for the corresponding means). Main effects of set size were found for INC-NEU $[F(2,22)=4.7, p<.05]$, INC-CONTR $[F(2,22)=10.9, p<.001]$, NEU CONTR $[F(2,22)=6.4, p<.01]$, CONTR - CONGR $[F(2,22)=6.1, p<.01]$, and NEU -CONGR $[F(2,22)$ $=4.7, p<.05]$. No significant main effect of set size was found for the difference INC-CONGR. A $t$ test for correlated means showed that the interference effects NEU-CONTR in Set Size Conditions 2 and 8 (18 and $14 \mathrm{msec}$, respectively) did not differ significantly [t(11) $=0.99$ ].

To examine the effects of practice within sessions, a separate analysis of variance was run with blocks $(1,2$, 3 , and 4$)$, set size (2, 4, and 8 ), and distractor conditions (INC, NEU, CONTR, and CONGR) as within-subjects factors. Neither the main effect of blocks nor any of the interactions involving this factor reached significance. The data showed that the pattern of facilitation and interference obtained in the overall analysis was already apparent in the first block of trials. Of interest is the finding that in the eight-target condition the interference defined as INC-NEU gradually increases from Block 1 to Block 3 (mean interference values in the four blocks respectively: $2,8,21$, and $13 \mathrm{msec}$ ).

\section{Discussion}

The results of this experiment are quite similar to the findings of Proctor and Fober (1985), Taylor (1977), and La Heij et al. (1985). First, the interference effect, both when defined as INC-NEU and when defined as INC-CONTR, decreases with increasing set size. Second, the facilitation effect, both when defined as CONTR - CONGR and when defined as NEU-CONGR, increases with set size. The results also show that the difference between the NEU and CONTR conditions does not seem to change with set size, since the interference values NEU-CONTR obtained with Set Sizes 2 and 8 do not differ significantly (18 and $14 \mathrm{msec}$, respectively). We will further discuss these effects in the General Discussion.

Two other aspects of the data are worth mentioning. First, in the overall analysis, a small, but significant, difference was found between the mean RTs of the various set size conditions. This finding is in accordance with the results of Gellatly and Gregg (1974) and Gholson and Hohle (1968b), who showed that even with highly compatible responses a small increase in mean RT can be observed with an increasing number of target alternatives. This increase appears to be restricted to very small set sizes (from two to approximately four). Second, the increase in interference defined as INC-NEU with blocks of trials in the eight-target condition suggests that the distinction between distractor letters that are used as targets in the experiment and distractor letters that are not used as targets has to be learned: a difference between the INC and NEU conditions starts to arise in the second block of trials.
Table 3

Stimulus Material Used in Experiment 2

\begin{tabular}{|c|c|c|c|}
\hline \multicolumn{2}{|c|}{$\begin{array}{l}\text { Picture Labels/ } \\
\text { Distractor Words }\end{array}$} & \multirow{2}{*}{$\begin{array}{c}\begin{array}{c}\text { Neutral } \\
\text { Distractors }\end{array} \\
\text { DIAMOND }\end{array}$} & \multirow{2}{*}{ Control } \\
\hline HEART & STAR & & \\
\hline CLOVER & TRIANGLE & SQUARE & \#\#\#\#\# \\
\hline CIRCLE & ARROW & CROSS & \#\#\#\#\# \\
\hline SPIRAL & RECTANGLE & ELLIPSE & \#\#\#\#\# \\
\hline
\end{tabular}

Note-Stimuli were combinations of a line drawing and a character string within the same row.

\section{EXPERIMENT 2}

Experiment 2 was set up to be as similar as possible to Experiment 1, except that in this experiment a naming task was used instead of a reading task. Eight simple line drawings were used as targets; 12 names of line drawings were used as distractor words (see Table 3). Pictures were chosen instead of colors for two reasons. First, simple line drawings show a greater similarity to the letter material used in Experiment 1. Second, it proved to be difficult to compose a satisfying set of 8 colors and 12 color names without introducing ambiguity into the verbal labeling of the colors (e.g., red-orange, blue-purple, gold-yellow). Since there is strong evidence for a functional similarity between picture-word interference tasks and Stroop tasks (see, e.g., W. R. Glaser \& Düngelhoff, 1984; Lupker, 1979), the results of this experiment can probably be generalized to color-naming tasks.

\section{Method}

Subjects. Twelve University of Leiden students served as paid subjects. All had normal or corrected-to-normal vision.

Materials. Table 3 gives the names of the pictures and the distractor words used. The targets were eight easily distinguishable line drawings. The distractor words in the INC and CONGR conditions were the eight verbal labels CIRKEL (CIRCLE), PIJL (ARROW), DRIEHOEK (TRIANGLE), KLAVER (CLOVER), RECHTHOEK (RECTANGLE), SPIRAAL (SPIRAL), HART (HEART), and STER (STAR). The four distractor words in the NEU condition were the names of line drawings that could have been used as targets in the experiment: KRUIS (CROSS), VIERKANT (SQUARE), ELLIPS (ELLIPSE), and RUTT (DIAMOND). The eight distractor words that were part of the response set and the four neutral distractor words were matched for imageability (see Lupker, 1979) and word length. Imagery values for the Dutch words were available for seven of the eight distractor words that were part of the response set and for three of the four neutral distractor words. The mean imageability values of these two sets were 6.24 and 6.35 , respectively (Van Loon-Vervoorn, 1985). The mean lengths of the words in these two sets were 6 and 5.75 letters, respectively.

As in Experiment 1, the eight targets were assigned to four pairs, and each of the neutral distractor words was assigned to one of these pairs. The distractor conditions were the same as those used in Experiment 1: INC (e.g., a circle with the word ARROW); NEU (e.g., a circle with the word CROSS); CONTR (e.g., a circle with the string \#\#\#\#\#); CONGR (e.g., a circle with the word CIRCLE). Apparatus. The apparatus was identical to the one used in Experiment 1.

Procedure. At the start of the first session, the subject was shown the eight target pictures and asked to name them. In $13.5 \%$ of the 
cases, a name was given that was different from the one that had to be used in the experiment (e.g., SNAIL instead of SPIRAL; ROUND instead of CIRCLE). In these cases, the subject was asked to adopt the names given in Table 3.

The line drawings were centered in an imaginary square $1.2^{\circ}$ of visual angle in size. The words subtended $1.3^{\circ}$ of visual angle (four-letter word) to $2.9^{\circ}$ of visual angle (nine-letter word). The distance between the word and the nearest contour of the imaginary square was $0.57^{\circ}$ of visual angle. The two barmarkers at both sides of the centrally displayed word were $4.18^{\circ}$ of visual angle apart. In all further respects, the procedure was identical to the one in Experiment 1. So, a distractor word appeared at the fixation point followed, after $50 \mathrm{msec}$, by a target picture shown for $100 \mathrm{msec}$. The target picture could appear either above or below the central distractor word. The subjects were asked to name the picture as fast and as accurately as possible while ignoring the distractor word.

\section{Results}

The raw data were treated as follows: First, RTs longer than $1,500 \mathrm{msec}$ were excluded. This criterion differed from the one used in Experiment 1, since RTs between 1,000 and $1,500 \mathrm{msec}$ were considered to be within the range that could be expected in this kind of a naming task. Next, for each subject, the means and standard deviations were calculated for each of the 12 experimental conditions (three response set sizes $\times$ four distractor conditions). RTs that deviated by more than three standard deviations from their cell mean were excluded. The remaining RTs were used in the calculations of the means per subject. The 1,500-msec criterion, the 3-SD criterion, and the trials in which the voice key failed to trigger or triggered too early accounted for $0.03 \%, 0.9 \%$, and $0.6 \%$ of the data, respectively. Table 4 shows the mean RTs and percentages of errors in the various conditions (see also Figure 1). Since the error percentages were small and generally in accordance with the results of the response latency measures, no statistical analysis was performed on these data.

An overall analysis of variance was run over the mean RTs with order of presentation of the set size conditions (six possible orders) as a between-subjects factor and set size $(2,4$, and 8$)$ and distractor conditions (INC, NEU, CONTR, and CONGR) as within-subjects factors. Significant main effects were obtained for the factor of number of target alternatives $[F(2,12)=75.5, p<.001]$ (mean RTs were 488, 578, and $614 \mathrm{msec}$ in Set Size Conditions 2,4 , and 8 , respectively) and for the factor of distractor conditions $[F(3,18)=101.9, p<.001]$ (mean RTs were 586, 578, 558, and $518 \mathrm{msec}$ in the INC, NEU, CONTR, and CONGR conditions, respectively).

Interaction effects were obtained between set size conditions and order of presentation of the set size conditions $[F(10,12)=3.3, p<.05]$ (this reflects a decrease of mean RT with days) and between set size conditions and the distractor conditions $[F(6,36)=6.5, p<.01]$ (the RTs corresponding to this interaction are given in Table 4).

As in Experiment 1, separate analyses of variance were run over the difference scores INC-NEU, INC-CONTR, INC-CONGR, NEU-CONTR,
Table 4

Mean Reaction Times in Milliseconds and Percentages of Errors (in Parentheses) per Target Set Size and Distractor Condition in Experiment 2

\begin{tabular}{ccccc}
\hline & \multicolumn{4}{c}{ Distractor Condition } \\
\cline { 2 - 5 } Set Size & Incongruent & Neutral & Control & Congruent \\
\hline 2 & $516(3.9)$ & $499(2.2)$ & $479(0.9)$ & $460(0.8)$ \\
4 & $605(3.4)$ & $596(3.5)$ & $576(1.6)$ & $534(1.2)$ \\
8 & $636(2.2)$ & $639(2.9)$ & $618(3.1)$ & $562(1.6)$ \\
\hline
\end{tabular}

NEU-CONGR, and CONTR - CONGR, with set size as the within-subjects factor (see Table 5 for the corresponding means). Main effects of set size were found for INC-NEU $[F(2,22)=8.3, p<.01]$, INC-CONTR $[F(2,22)=4.6, p<.05]$, CONTR-CONGR $[F(2,22)=30.7, p<.001]$, and NEU-CONGR $[F(2,22)=9.5, p<.01]$. The difference of INC-CONGR failed to reach significance $(p>.10)$. The interference effect NEU-CONTR did not show a main effect for the factor set size $(p>.90)$.

A separate analysis of variance was run with blocks (1, $2,3$, and 4$)$, set size conditions $(2,4$, and 8 ), and distractor conditions (INC, NEU, CONTR, CONGR) as within-subjects factors. Neither the main effect of blocks nor any of the interactions involving this variable reached significance. The data showed that the overall pattern of facilitation and interference was already apparent in the first block of trials.

\section{Discussion}

In the NVB variant of the task examined in this experiment, an increase in the target set size resulted in a strong increase in the overall mean RT. With respect to the context effects, the following observations were made: First, the interference effect, both when defined as INC - NEU and when defined as INC-CONTR, decreases with increasing set size. Second, the facilitation effect, both when defined as NEU-CONGR and when defined as CONTR - CONGR, increases with increasing set size. Third, the difference NEU-CONTR remained constant. We will return to these findings in the General Discussion.

One aspect of the interference effect defined as INC-NEU is worth mentioning here. This interference effect is apparently due to the different status of the corresponding distractor elements in the experiment. The distractors in the INC condition are associated with one of the possible responses in the experiment, whereas the distractors in the NEU condition are not. It is evident that, with increasing target set size, it will become more difficult to distinguish these two types of distractors. Of importance is that the present results and those of $\mathrm{La} \mathrm{Heij}$ et al. (1985) indicate that the difference between the INC and NEU conditions disappears when the number of target alternatives is somewhere between 6 and 12 . This number might be related to the maximum number of items that can be held in short-term memory (Miller, 1956). This finding seems to imply that the interference of a distractor due to its presence in the set of possible targets 
in the experiment is a factor of importance only in tasks in which the number of target alternatives is smaller than approximately 10-that is, in the Stroop task, in which the number of target alternatives is often somewhere between 2 and 5 , but not in the majority of picture-word interference tasks, in which the target set size is often larger than 12 .

\section{GENERAL DISCUSSION}

The most obvious difference between the results of Experiments 1 and 2 lies in the effect of target set size on overall response latency (see Figure 1). In the reading task of Experiment 1, this effect was small and only just reached significance (a difference of $14 \mathrm{msec}$ between Set Sizes 2 and 8), whereas in the naming task of Experiment 2 this effect was much larger (a difference of $126 \mathrm{msec}$ between Set Sizes 2 and 8). It should be noted that in the two-target condition almost no difference was observed between the mean RTs in the reading and naming tasks. These findings nicely replicate the results reported by Gellatly and Gregg (1974) and Gholson and Hohle (1968b).
The main objective of the present study was to examine the effect of target set size on facilitation and interference effects in the VB and NVB variants of the task under investigation. As discussed in the introduction, manipulation of target set size seemed to have differential effects in both variants. However, the results of the present study show that when procedural differences are discarded the effects of set size on facilitation and interference values are remarkably similar in both variants. Increasing the target set size had the following consequences in both experiments: first, the interference effect decreased, both when defined as INC-NEU and when defined as INC-CONTR; second, the facilitation effect increased, both when defined as CONTR - CONGR and when defined as NEU-CONGR; and third, the difference NEU-CONTR was not affected. Apparently, in both letter-reading and picture-naming tasks, an increase in target set size results in a tradeoff between interference and facilitation. The same phenomenon can be observed in the letter-identification tasks reported by Taylor (1977), who used a neutral condition (the target letter accompanied by the distractor $\mathrm{O}$ ) as a baseline, and in a letter-identification task reported by Proctor and Fober

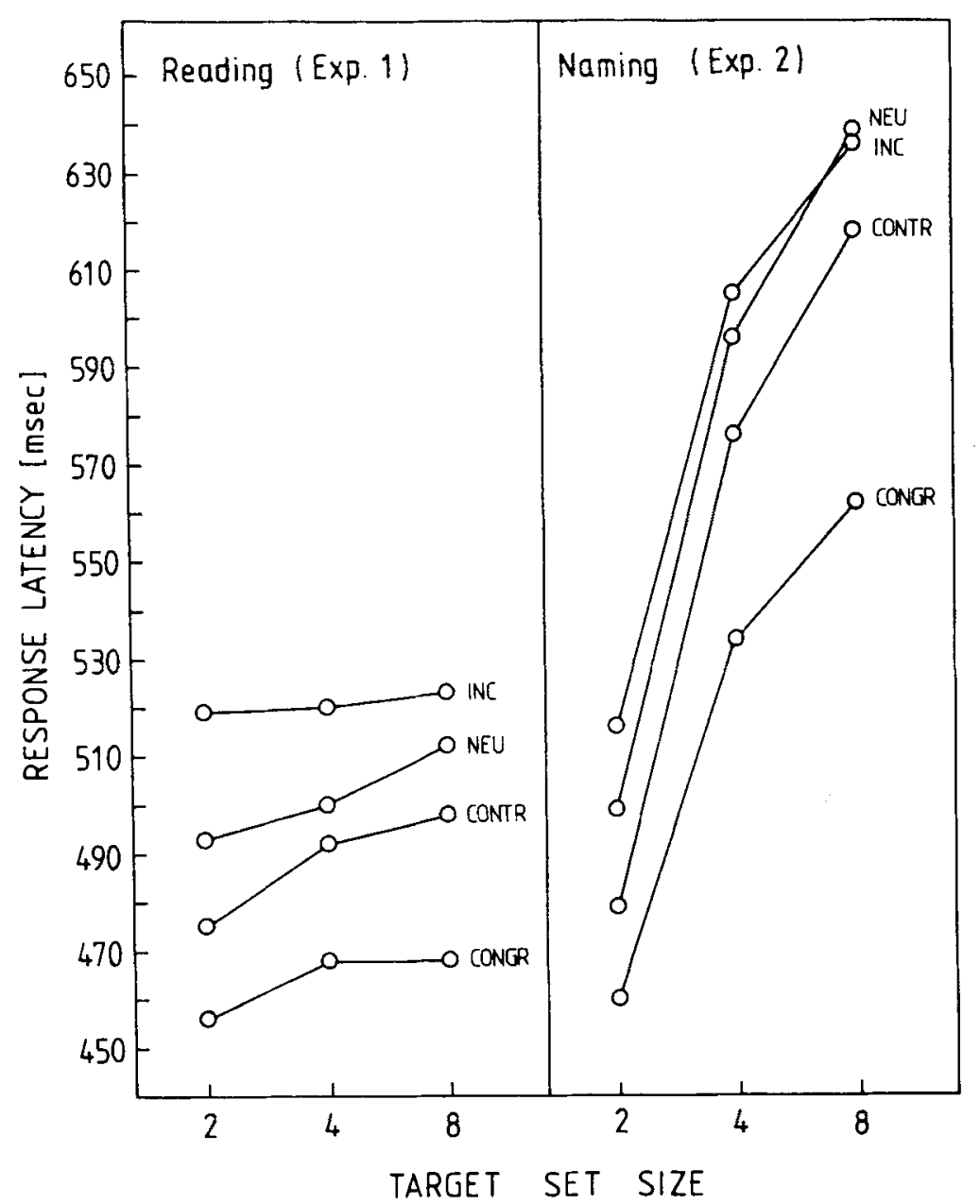

Figure 1. Mean response latencies in the various distractor conditions and target set size conditions of Experiments 1 and 2. 
(1985), when their control condition (the target letter accompanied by an asterisk) was used as a baseline.

In the remainder of this discussion, a simple model will be presented that is capable of accounting for most of the effects observed in Experiments 1 and 2. The model, furthermore, generates predictions concerning similarities and differences between the results of both experiments. Subsequent analyses of variance over the combined results of Experiments 1 and 2 generally confirmed these predictions.

The model is a variant of the logogen model presented by Morton (1969). It borrows freely from changes and refinements of the model proposed by Morton and Chambers (1973) and Van der Heijden (1981), and shows clear resemblances to the continuous flow conception model of C. W. Eriksen and Schultz (1979). The general characteristics of the model are the following. (1) For each of the stimulus elements in the present experiments, a logogen exists that can be viewed as a device that counts the evidence for the verbal response associated with that logogen. (Following the distinction made by Warren and Morton, 1982, this type of logogen could be called an "output logogen."') (2) Some time after presentation of the stimulus elements, the counts in the corresponding logogens start to increase. (3) A response is made available when the activation of a logogen reaches a criterion value, or "evocation threshold." (4) This criterion value depends upon, among other things, the number of times the corresponding response has been made in the recent past; the more often it has been made, the lower the criterion level. (5) The execution of the response to the target is delayed when the response corresponding to the noise element is available earlier. (6) The presentation of a congruent distractor results in a stronger increase in activation of the logogen corresponding to the target, as compared with the situation in which the target is presented alone. (7) The increase in activation of the verbal output logogen is stronger when the target is verbal than when the target is nonverbal.

These general characteristics of the model were made more specific in order to allow for predictions concerning the effects of the factors of verbal targets (Experiment 1) versus nonverbal targets (Experiment 2) and target set size $(2,4$, and 8$)$, and the interaction between these two factors. First, it is assumed that for each stimulus element, including the \# sign, a logogen exists.

Second, some time after presentation of the stimulus, the activation levels in the corresponding logogens start to increase. For the sake of simplicity, a linear increase is assumed. ${ }^{1}$ The size of the increase in activation level per unit of time equals $\Delta S$. With respect to the size of $\Delta S$, the following two assumptions are made: $\Delta S$ is larger when the corresponding stimulus element is verbal than when the corresponding stimulus element is nonverbal (see Van der Heijden, 1981), and $\Delta S$ is larger when the target is accompanied by a congruent distractor than when it is presented in isolation. The latter characteristic of the model is in line with Grice and Gwynne's (1985) sugges- tion that an identical noise element that is presented in advance of the target induces a "more rapid growth of the associative strength leading to response evocation" (p. 500).

Third, the criterion level of a logogen depends upon the number of times the response corresponding to that logogen has been made in the recent past. For our experiments, this implies that the criterion level increases with an increasing number of target alternatives. Since no responses are made to the neutral distractors or to the \# signs used in the control condition, it is assumed that the criterion value of the logogens corresponding to these elements is not affected by the size of the target set. The assumption could be made that the criterion levels of the logogens that correspond to the neutral distractors are somewhat larger than the criterion levels of the logogens that correspond to the targets in a response set of eight. ${ }^{2}$ With respect to the control condition, it could be assumed that the criterion level is higher than the criterion levels of the letters used as stimulus material. (We will return to the assumptions concerning the control condition at the end of this discussion.)

Fourth, it is assumed that within the time range investigated in our experiments, the amount of interference of a noise element in the naming or reading of the target increases with increasing delay between the availability of the response to the distractor $(T d)$ and the availability of the response to the target $(T t)$. That is, the interference increases with an increasing value of $(T t-T d){ }^{3} \mathrm{~A}$ similar suggestion was made by Morton and Chambers (1973). In their account of Stroop interference, these authors noted that "the presence of another stimulus value in a different attribute will interfere in proportion to the relative speeds of naming the attributes"' (p. 396).

Fifth, it is assumed that the amount of facilitation increases with $\left(T t-T t^{\prime}\right)$, in which $T t^{\prime}$ is the time at which the criterion level of the target logogen is reached when the target is accompanied by a congruent distractor.

Figure 2 depicts the main characteristics of the model. The dashed horizontal lines represent the three criterion levels corresponding to the three target set size conditions.

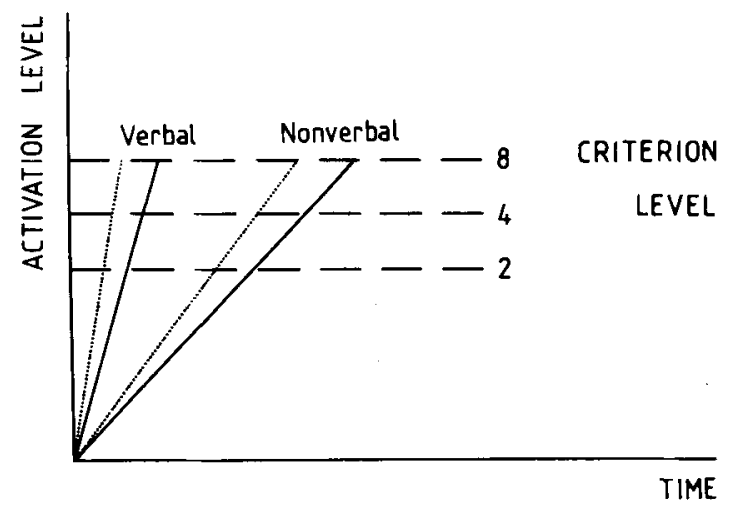

Figure 2. Hypothetical time courses of activation of a logogen. For further explanation, see text. 
The eight-target condition has the highest criterion value, and the two-target condition, the lowest. The solid and dotted diagonal lines represent increases in the activation levels of the logogens. The slope of these lines depends upon (1) whether the target stimulus is verbal or nonverbal, and (2) whether the target is preceded by a congruent distractor element (dotted lines) or not (solid lines).

As will be clear from Figure 2, these characteristics of the model account for: (1) a larger mean RT in naming tasks than in reading tasks, (2) an increase of mean $\mathrm{RT}$ with target set size in naming and reading tasks, and (3) a stronger increase of mean RTs with target set size in naming tasks than in reading tasks. All these characteristics were present in our data and are described in previous paragraphs.

The differences between the various distractor conditions used in Experiments 1 and 2 can easily be derived from the model. If the criterion value that has to be reached is $C$ and the increase in activation per unit of time is $\Delta S$, the criterion will be reached at time $T=C / \Delta S$. The times at which the target, the incongruent distractor, the neutral distractor, and the control distractor reach their criterion values equal $T t, T i, T n$, and $T c$, respectively. The corresponding criterion values equal $C t, C i, C n$, and $C c$, respectively. The corresponding increases in activation level per unit of time equal $\Delta S t, \Delta S i, \Delta S n$, and $\Delta S c$, respectively. The increase of activation level in the target logogen when a congruent distractor is presented equals $\Delta S t^{\prime}\left(\Delta S t^{\prime}>\Delta S t\right)$; the time at which the target reaches the criterion level in the congruent condition equals $T t^{\prime}\left(T t^{\prime}<T t\right)$.

Since the interference due to the presence of a distractor is assumed to increase with the amount of delay between the time at which the responses to the distractor $(T d)$ and the target $(T t)$ become available, the amount of interference will increase with the difference $(T t-T d)$. If the criterion level of the distractor equals $C d$ and the increase in activation of the distractor per unit of time equals $\Delta S d,(T t-T d)=C t / \Delta S t-C d / \Delta S d$. The amount of facilitation due to the presence of a congruent distrac- tor will increase with the difference, $\left(T t-T t^{\prime}\right)=$ $C t / \Delta S t-C t / \Delta S t^{\prime}$.

The difference in mean RT between two distractor conditions can now be viewed as the difference between the amounts of interference caused by the distractors in the two conditions, or, if the congruent distractor condition is involved, as the sum of the interference obtained in one distractor condition and the facilitation obtained in the congruent distractor condition. For example, the difference INC -NEU will increase with the difference $(T t-T i)-$ $(T t-T n)$; the difference INC-CONGR will increase with the sum $(T t-T i)+\left(T t-T t^{\prime}\right)$. These differences or sums can be stated in terms of criterion levels $(C)$ and accumulation of activation per unit of time $(\Delta S)$. In the interpretation of these differences or sums, it should be remembered that the factor of target set size affects only $C t$ and $C i$ ( $C n$ and $C c$ are constants), and that the factor of verbal versus nonverbal targets affects only $\Delta S t(\Delta S i$ and $\Delta S n$ are constants, since all incongruent and neutral distractors are verbal; $\Delta S c$ is constant, since the control character is always nonverbal).

For each of the six possible comparisons between the four distractor conditions, the effect of the factors of verbal versus nonverbal targets and of target set size and the effect of the interaction between these two factors can be predicted. These predictions were tested in analyses of variance over the difference scores with verbal versus nonverbal targets (Experiment 1 vs. Experiment 2) as a between-subjects factor and target set size $(2,4,8)$ as a within-subjects factor. The mean difference scores and the results of the analyses of variance are given in Table 5 .

The model makes the following predictions:

INC-NEU:

$$
(T t-T i)-(T t-T n)=(T n-T i)=C n / \Delta S n-C i / \Delta S i .
$$

$\mathrm{Ci}$ increases with target set size. So the model predicts that the difference INC-NEU will decrease with set size.

Table 5

Differences Between the Mean RTs in the Four Distractor Conditons per Target Type and Set Size, and the Results of the Analyses of Variance

\begin{tabular}{|c|c|c|c|c|c|c|c|c|c|}
\hline \multirow[b]{3}{*}{ Set Size } & \multirow{2}{*}{\multicolumn{3}{|c|}{$\begin{array}{c}\text { Verbal } \\
\text { Target } \\
\text { (Experiment 1) }\end{array}$}} & \multirow{2}{*}{\multicolumn{3}{|c|}{$\begin{array}{c}\text { Nonverbal } \\
\text { Target } \\
\text { (Experiment 2) }\end{array}$}} & \multicolumn{3}{|c|}{$\begin{array}{l}\text { Significance Levels of Main Effects } \\
\text { and Interaction }\end{array}$} \\
\hline & & & & & & & Set & Verbal/ & Set Size $x$ \\
\hline & 2 & 4 & 8 & 2 & 4 & 8 & Size & Nonverbal & \\
\hline \multicolumn{10}{|l|}{ Comparison } \\
\hline INC-NEU & 26 & 20 & 11 & 17 & 9 & -3 & $p<.001$ & $p<.05^{*}$ & n.s. \\
\hline INC-CONTR & 44 & 28 & 25 & 37 & 29 & 18 & $p<.001$ & n.s. & n.s. \\
\hline INC-CONGR & 63 & 52 & 55 & 56 & 71 & 74 & n.s. $†$ & n.s. $\dagger$ & $p<.05$ \\
\hline NEU-CONTR & 18 & 8 & 14 & 20 & 20 & 21 & n.s. & n.s. & n.s. \\
\hline NEU-CONGR & 37 & 32 & 44 & 39 & 62 & 77 & $p<.001$ & $p<.01$ & $p<.01$ \\
\hline CONTR-CONGR & 19 & 24 & 30 & 19 & 42 & 56 & $p<.001$ & $p<.01$ & $p<.001$ \\
\hline
\end{tabular}

Note-n.s. $=$ effect does not reach significance $(p>.10) . \quad$ *Main effect not predicted by the model. †Main effect predicted by the model, but not reaching significance. 
Since all other terms are independent of both set size and target type, no differences are expected between Experiments 1 and 2 . The analysis of variance is consistent with two of the predictions but shows one unexpected result: a main effect of verbal versus nonverbal targets.

INC-CONTR:

$$
(T t-T i)-(T t-T c)=(T c-T i)=\underline{C c / \Delta S c-C i / \Delta S i} .
$$

$C i$ increases with target set size. So the model predicts that this difference will decrease with set size. No differences are expected between Experiments 1 and 2. The data and the results of the analysis of variance are in accordance with these predictions.

INC-CONGR:

$$
\begin{aligned}
(T t-T i)+\left(T t-T t^{\prime}\right) & =2 T t-T t^{\prime}-T i \\
& =2 C t / \Delta S t-C t / \Delta S t^{\prime}-C i / \Delta S i .
\end{aligned}
$$

$\Delta S t^{\prime}>\Delta S t$, so $\Delta S t^{\prime}=k \cdot \Delta S t(k>1)$; this gives:

$$
(2 C t-C t / k) / \Delta S t-C i / \Delta S i \text {. }
$$

When the target and distractor are verbal (Experiment 1) $(\Delta S i=\Delta S t$ and $C i=C t)$ :

$$
(C t-C t / k) / \Delta S t=\underline{(1-1 / k) C t / \Delta S t} .
$$

When the target is nonverbal (Experiment 2) $(\Delta S i=$ $m \cdot \Delta S t, m>1$, and $C i=C t$ ):

$$
(2 C t-C t / k-C t / m) / \Delta S t=\underline{(2-1 / k-1 / m) C t / \Delta S t} .
$$

$C t$ increases with target set size. Since $k>1$ and $m>1$, the difference INC-CONGR will increase with target set size. Since $\Delta S t$ is larger when the target is verbal than when it is nonverbal, the increase in this difference with target set size will be larger when the target is nonverbal (Experiment 2) than when it is verbal (Experiment 1). So the model predicts main effects of set size and of verbal versus nonverbal targets and an interaction between these factors. The trends in the data are in accordance with these predictions. In the analysis of variance, only the predicted interaction reached significance.

\section{NEU-CONTR:}

$$
(T t-T n)-(T t-T c)=T c-T n=C c / \Delta S c-C n / \Delta S n .
$$

This difference is independent of the size of the target set and independent of the factor of verbal versus nonverbal targets. The data and the results of the analysis of variance are completely in accordance with these predictions.

NEU-CONGR:

$$
\begin{aligned}
(T t-T n)+\left(T t-T t^{\prime}\right) & =2 T t-T t^{\prime}-T n \\
& =(2 C t-C t / k) / \Delta S t-C n / \Delta S n \\
& =(2-1 / k) C t / \Delta S t-C n / \Delta S n .
\end{aligned}
$$

$C t$ increases with target set size. Therefore, the difference NEU-CONGR increases with target set size. $\Delta S t$ is larger for verbal targets than for nonverbal targets. Therefore, the increase in this difference with target set size will be larger in Experiment 2 than in Experiment 1. The data and the results of the analysis of variance are completely in accordance with these predictions.

\section{CONTR-CONGR:}

$$
\begin{aligned}
(T t-T c)+\left(T t-T t^{\prime}\right) & =2 T t-T t^{\prime}-T c \\
& =(2 C t-C t / k) / \Delta S t-C c / \Delta S c \\
& =(2-1 / k) C t / \Delta S t-C c / \Delta S c .
\end{aligned}
$$

The same predictions as for the difference NEU-CONGR. The data and the results of the analysis of variance are completely in accordance with these predictions.

So, with only two parameters (rate of accumulation of activation and criterion level) and relatively few assumptions, the model accounts for the effects of target set size, verbal versus nonverbal targets, and the interaction between these two factors. As shown in Table 5, three effects were not in accordance with the predictions. The main effect of verbal versus nonverbal targets on the difference INC -NEU could be due to the fact that the words used in the incongruent and neutral conditions of Experiment 2 could not be matched perfectly on all relevant dimensions. An alternative explanation could be given in terms of a greater difficulty in localizing the target in the INC condition of Experiment 1; in this 'condition, both stimulus elements are letters and potential targets.

It should be clear that the assumption of the model concerning the relationship between the times that target and distractor reach their criterion levels $(T t-T d)$ and the amount of interference observed is completely in accord with Ray's (1974) argument, which was discussed in the introduction. She predicted that the amount of interference in a Stroop task should increase with an increasing target set size because of an increasing delay between the times at which the responses to the word and the color become available. If our model is completely in line with this conception, why does it predict a decrease in interference with increasing set size?

If interference is defined as INC-NEU, the answer is clear. When the number of target alternatives is small, the incongruent distractor has a lower criterion level than the neutral distractor. Consequently, the response to the incongruent distractor will be available earlier than the response to the neutral distractor and for that reason will induce more interference. If the number of target alternatives is large, however, the criterion levels of the incongruent and neutral distractors hardly differ. For that reason, these distractors will induce an equal amount of interference, resulting in almost identical mean response latencies in the incongruent and neutral conditions. 
When interference is defined as INC-CONTR, the predictions of the model are dependent upon the assumption made concerning the control character. In the predictions of the model derived above, it was assumed that the control character (the \# sign) made a response available that interfered with the response to the target. Since the time at which the response to the control character becomes available is independent of the target set size, and the time at which the response to the target becomes available increases with target set size, the amount of interference induced by the control character will increase with target set size. In fact, the only difference between the control condition and the neutral condition in the model is that the response to the control character will become available later than will the response to the neutral letter. It should be clear that if this interpretation of the control condition is correct, it is questionable whether this condition is an appropriate baseline from which facilitation and interference can be assessed (see Proctor \& Fober, 1985 , for similar conclusions concerning their control condition). An appropriate baseline condition should show no interference with the response to the target or, at least, equal amounts of interference in the various target set size conditions. If such a control condition could be found, the model presented above would predict (1) no change in interference defined as INC-CONTR with set size in Experiment 1 [the amount of interference would be proportional to the difference $(T t-T i)$, a difference that is independent of the set size when target and distractor are both verbal], and (2) an increase in interference defined as INC-CONTR with set size in Experiment 2 [the amount of interference is proportional to $(T t-T i)$, a difference that increases with set size when the target is nonverbal].

If the alternative interpretation that our control condition is appropriate is supported, however, the assumptions made in the model concerning the relationship between time delays and amount of interference need to be reconsidered. For our present purposes, however, the theoretical issue of the appropriateness of the control condition is not really essential. What the present results show is that when baseline conditions are employed that are widely used in the type of task under consideration, the difference scores obtained in reading and naming tasks show similar changes with increasing target set size. The question of whether the difference scores in the present study and those in the studies of, for example, Proctor and Fober (1985) and Taylor (1977) reflect a "true" decrease in interference and a "true" increase in facilitation remains a matter for further investigation.

Finally, the model does not say anything with respect to the possible mechanisms responsible for the interference effects observed. Recent studies by C. W. Eriksen, Coles, Morris, and O'Hara (1985) and Coles, Gratton, Bashore, C. W. Eriksen, and Donchin (1985) strongly suggest that at least part of the interference is due to the (partial) activation of the response to the distractor, resulting in either an error or a time-consuming correction.

\section{REFERENCES}

Coles, M. G. H., Gratton, G., Bashore, T. R., Eriksen, C. W., \& Donchin, E. (1985). A psychophysiological investigation of the continuous flow model of human information processing. Journal of Experimental Psychology: Human Perception \& Performance, 11, 529-553.

Eriksen, B. A., \& Eriksen, C. W. (1974). Effects of noise letters upon the identification of a target letter in a nonsearch task. Perception \& Psychophysics, 16, 143-149.

Eriksen, C. W., Coles, M. G. H., Morris, L. R., \& O'Hara, W. P. (1985). An electromyographic examination of response competition. Bulletin of the Psychonomic Society, 23, 165-168.

ERIKSEN, C. W., \& SCHULTZ, D. W. (1979). Information processing in visual search: A continuous flow conception and experimental results. Perception \& Psychophysics, 25, 249-263.

Flowers, J. H., \& WiLcox, N. (1982). The effect of flanking context on visual classification: The joint contribution of interactions at different processing levels. Perception \& Psychophysics, 32, 581-591.

Fraisse, P. (1969). Why is naming longer than reading? Acta Psychologica, 30, 96-103.

Gellatly, A. R. H., \& GregG, V. H. (1974). The effect of set size on the latency to name words. Acta Psychologica, 38, 93-99.

Gholson, B., \& Hohle, R. H. (1968a). Choice reaction times to hues printed in conflicting hue names and nonsense words. Journal of $E x-$ perimental Psychology, 76, 413-418.

GHolson, B., \& HohlE, R. H. (1968b). Verbal reaction times to hues vs hue names and forms vs form names. Perception \& Psychophysics, 3, 191-196.

Glaser, M. O., \& Glaser, W. R. (1982). Time course analysis of the Stroop phenomenon. Journal of Experimental Psychology: Human Perception \& Performance, 8, 875-894.

Glaser, W. R., \& Düngelhoff, F.-J. (1984). The time course of picture-word interference. Journal of Experimental Psychology: Human Perception \& Performance, 10, 640-654.

Golden, C. J. (1974). Effect of differing numbers of colors on the Stroop color and word test. Perceptual \& Motor Skills, 39, 550.

Grice, G. R., Boroughs, J. M., \& Canham, L. (1984). Temporal dynamics of associative interference and facilitation produced by visual context. Perception \& Psychophysics, 36, 499-507

GrICE, G. R., \& GWYNNE, J. W. (1985). Temporal characteristics of noise conditions producing facilitation and interference. Perception \& Psychophysics, 37, 495-501.

GutTentag, R. E., \& Haith, M. M. (1978). Automatic processing as a function of age and reading ability. Child Development, 49, $707-716$.

KLEIN, G. S. (1964). Semantic power measured through the interference of words with color-naming. American Journal of Psychology, 77, 576-588..

La Heis, W., Van der Heijden, A. H. C., \& Schreuder, R. (1985). Semantic priming and Stroop-like interference in word-naming tasks. Journal of Experimental Psychology: Human Perception \& Performance, 11, 62-80.

LUPKER, S. J. (1979). The semantic nature of response competition in the picture-word interference task. Memory \& Cognition; 7, 485-495.

MCClaiN, L. (1983). Effects of response type and set size on Stroop color-word performance. Perceptual \& Motor Skills, 56, 735-743.

MiLleR, G. A. (1956). The magical number seven, plus or minus two: Some limits on our capacity for processing information. Psychological Review, 63, 81-97.

Morton, J. (1969). Interaction of information in word recognition. Psychological Review, 76, 165-178.

Morton, J., \& Chambers, S. M. (1973). Selective attention to words and colours. Quarterly Journal of Experimental Psychology, 25, 387-397.

Proctor, R. W. (1978). Sources of color-word interference in the Stroop color-naming task. Perception \& Psychophysics, 23, 413-419.

Proctor, R. W., \& FOBER, G. W. (1985). Repeated-stimulus superiority and inferiority effects in the identification of letters and digits. Perception \& Psychophysics, 38, 125-134. 
RAY, C. (1974). The manipulation of color response times in a colorword interference task. Perception \& Psychophysics, 16, 101-104.

Rosinsk,, R. R., Golinkoff, R. M., \& KuKISH, K. S. (1975). Automatic semantic processing in a picture-word interference task. Child Development, 46, 247-253.

StIRLING, N., \& ColtheART, M. (1977). Stroop interference in a letter naming task. Bulletin of the Psychonomic Society, 10, 31-34.

STROOP, J. R. (1935). Studies of interference in serial verbal reactions. Journal of Experimental Psychology, 18, 643-661.

TAYLOR, D. A. (1977). Time course of context effects. Journal of Experimental Psychology: General, 4, 404-426.

VAN DER HEIJDEN, A. H. C. (1981). Short-term visual information forgetting. London: Routledge \& Kegan Paul.

Van der Heijden, A. H. C., Malhas, M. S. M., \& Van den RoovaART, B. P. (1984). An empirical interletter confusion matrix for continuous-line capitals. Perception \& Psychophysics, 35, 85-88.

VAN LOON-VERVOORN, W. A. (1985). Voorstelbaarheidswaarden van Nederlandse woorden [Imageability values of Dutch words]. Lisse: Swets \& Zeitlinger.

WARREN, C., MORTON, J. (1982). The effects of priming on picture recognition. British Journal of Psychology, 73, 117-129.

WILLIAMS, E. (1977). The effects of amount of information in the Stroop color-word test. Perception \& Psychophysics, 22, 463-470.

\section{NOTES}

1. It can be shown that identical predictions will be derived when, instead of a linear function, an exponential growth function of the form $c(t)=a-b e^{-\alpha t}$ is used.

2. This will probably be dependent upon the amount of practice with the target material. The increase in interference defined as INC-NEU with blocks of trials in the eight-target condition of Experiment 1 suggests that a difference between the criterion levels of the incongruent and neutral distractors arises in the second block of trials.

3. The relationship between the size of the interference effect and the delay between the availability of the responses to the distractor and the target could be interpreted in the following way. Interference could be viewed as an all-or-none phenomenon. If the response to the distractor element is made available before the response to the target, interference is obtained. If the target response is made earlier, no interference is obtained. If it is assumed that the moments at which the target and the distractor reach their criterion levels are distributed around a mean $\left(T t, T i, T n, T c\right.$, or $T t^{\prime}$ in our model), the chance that a distractor element will reach its criterion earlier than the target increases with an increasing delay between the moments at which the two responses become available.

(Manuscript received August 12, 1986;

revision accepted for publication December 31, 1986. ) 